\title{
Cocteau journaliste, sous la direction de Pierre-Marie Hèron et Marie-Ève Thérenty
}

\section{Mireille Brangé}

\section{(2) OpenEdition}

1 Journals

Édition électronique

URL : http://journals.openedition.org/studifrancesi/600

DOI : 10.4000/studifrancesi.600

ISSN : 2427-5856

Éditeur

Rosenberg \& Sellier

\section{Édition imprimée}

Date de publication : 1 avril 2015

Pagination : 191

ISSN : 0039-2944

\section{Référence électronique}

Mireille Brangé, " Cocteau journaliste, sous la direction de Pierre-Marie Hèron et Marie-Ève Thérenty », Studi Francesi [En ligne], 175 (LIX | I) | 2015, mis en ligne le 01 avril 2015, consulté le 18 septembre 2020. URL : http://journals.openedition.org/studifrancesi/600 ; DOI : https://doi.org/10.4000/ studifrancesi.600

Ce document a été généré automatiquement le 18 septembre 2020

\section{(c) (†) $\odot$}

Studi Francesi è distribuita con Licenza Creative Commons Attribuzione - Non commerciale - Non opere derivate 4.0 Internazionale. 


\title{
Cocteau journaliste, sous la direction de Pierre-Marie Hèron et Marie-Ève Thérenty
}

\author{
Mireille Brangé
}

\section{RÉFÉRENCE}

Cocteau journaliste, sous la direction de Pierre-Marie HÈRON et Marie-Ève THÉRENTY, Rennes, Presses Universitaires de Rennes, 2014 («Interférence»), pp. 262.

1 Le volume envisage les rapports de Cocteau avec le journalisme tout au long de sa carrière. Les quatorze contributions se distribuent en trois sections: «Images et stratégies médiatiques», «Le réel et ses questions», "Questions de genre», tandis que l'introduction des A. les replace dans la continuité chronologique de l'œuvre de Cocteau, en la liant à la quasi généralisation de la pratique du journalisme par les écrivains à partir des années Vingt, mais en traçant aussi trois grandes périodes: avant 1920, durant les années Trente, où se lit un désir de s'approcher, comme par son théâtre, d'un public plus large, et durant les années Cinquante où une production journalistique atomisée coexiste avec un désintérêt pour la presse et un mépris à l'encontre du journalisme dans le secret des pages du Passé défini.

2 Pour Cocteau, le journalisme devient le moyen de sa médiatisation, de la construction de son personnage, de son contrôle du champ littéraire autant que de la réception de ses œuvres. O. BARA examine Les débuts de Cocteau dans "Comœdia" et "Comœdia illustré" (1909-1912) (pp. 31-48), naissance à la fois médiatique et poétique de l'auteur, qui contribue à la revue par des chroniques - comme sur Les Ballets russes -, des nouvelles, des poèmes, mais surtout, position plus originale, par des dessins, ce qui le place dans le sillage de Sem et Cappiello. Si Cocteau a inauguré la pratique des articles-manifestes et des autojustifications de son œuvre dans «Parade» et dans «Excelsior», P.-M. HÉRoN montre comment il utilise ses contributions à «Carte blanche» pour revendiquer et 
assurer sa place dans le champ littéraire de l'après-guerre, en successeur d'Apollinaire (Les articles de clan dans "Carte Blanche", pp. 49-70). Interdit des pages de "Littérature» et de la «NRF», Cocteau utilise «Le Coq», sous les atours d'une revue Dada, dans un but radicalement opposé: l'affirmation d'un nécessaire classicisme français (P. SUTER, "Le Coq" et les revues Dada, pp. 171-184). J. тоUzoT étudie Jean Cocteau attaché de presse car dans les années Vingt, ne souhaitant pas que ses œuvres soient abandonnées à leur propre sort et à l'exemple du "système Cadum» expérimenté par Radiguet, Cocteau multiplie dans la presse les interventions autojustificatrices, préfaces, interviews, hommages à ses collaborateurs et même des textes confiés à des prête-noms. Après la seconde Guerre, malgré la «Haine du journalisme» (G. DUCREY, pp. 157-168), jugé règne de l'inexactitude, qui exsude de Passé défini, Cocteau écrit régulièrement dans la presse comme D. GUILLENTROPs le montre dans Jean Cocteau et "Les Lettres françaises" (pp. 79-96). Il rappelle aussi le rôle d'Aragon, grand contempteur de Cocteau journaliste avant la Guerre mais devenu directeur de l'hebdomadaire en 1953, et auquel Cocteau doit d'avoir été rayé de la liste noire établie à la Libération.

Les autres contributions portent sur l'écriture et le rapport au réel de Cocteau journaliste mais aussi sur le jeu des genres dans ses écrits. E. ATZENBERGER et J. VÉRILHAC étudient dans Le journalisme patriotique depuis le Toit: "Le Mot" de Paul Iribe et Jean Cocteau (pp. 99-114), la transformation du rôle de l'A., qui, en demeurant illustrateur de cet hybride entre revue d'art et journal satirique, endosse aussi le rôle de rédacteur en chef, d'éditorialiste, de chroniqueur, d'échotier et de reporter. Il s'agit aussi de ménager au patriotisme cocardier généralisé une forme élégante, «une décence dans la polémique» et «le tact de comprendre jusqu'où on peut aller trop loin» («Le Mot», 9 janvier 1915). Le mélange de réalité et de fiction auquel il s'essaie rejaillira à nouveau dans les années Trente. Tandis que F. AMY DE LA BRETÈQUE s'intéresse au Cinéma dans les séries de presse de Jean Cocteau (pp. 115-131), M.-E. THÉRENTY, De l'éternité pliée. Pratiques, postures et poétique du grand reportage chez Jean Cocteau (pp. 205-218) et M. CoLlomB, dans cette décennie, explorent la pratique du reportage à l'époque où cette figure attire bien des écrivains et leur procure succès. La première analyse les lieux communs auxquels Cocteau trouve plaisir et le second La séquence asiatique de "Mon premier voyage" (pp. 145-156) où, au contact de l'étrangeté radicale, la fiction se mêle au reportage. Dans tous les cas, il s'agit pour Cocteau de se rapprocher d'un public plus large et plus populaire. Autre avatar du journaliste-écrivain, la figure du chroniqueur, étudiée par $\mathrm{S}$. LINARÈs - Mémoriaux et éclats (sur "Portraits souvenirs") (pp. 133-143) -, s'infléchit avec Cocteau vers celle du mémorialiste, genre littéraire et non journalistique, ce qui explique la publication quasi immédiate d'un livre chez Grasset, et qui lui permet d'atteindre une détente dans l'écriture. M. BOUCHARENC s'intéresse à Cocteau publiciste (pp. 185-204), s'adonnant à la publicité commerciale, à l'instar d'autres célèbres contemporains (Colette, Desnos, Cendrars entre autres) et s'attache à définir le rôle singulier concédé par Cocteau à l'acte poétique. Enfin, dans les années Quarante, Ph. BAUDOIRE se concentre, dans "Le Foyer des artistes": un livre de Jean Cocteau de 1947 (pp. 233-258), sur l'articulation entre les articles de Cocteau publiés dans "Comœdia» pendant le Guerre et le livre qu'il en tire après une sélection qui doit beaucoup au nouveau contexte, tandis que A. WRONA (Fugues et figures: "Le Foyer des artistes", ou Cocteau portraitiste au quotidien, pp. 219-232) s'intéresse dans ce recueil aux traces qui demeurent du journalisme, en l'inscrivant dans la tradition des portraits publiés dans la presse depuis un siècle. 